\title{
Communication issues in 22q11.2 deletion syndrome: Children at risk
}

Cynthia B. Solot, $M A^{1,8}$, Marsha Gerdes, $P h D^{4,8}$, Richard E. Kirschner, $M D^{3,9,10}$, Donna M. McDonald-McGinn, MS $S^{5,6,9}$, Edward Moss, $P h D^{4,8}$, Michael Woodin, $P h D^{4,8}$, David Aleman, $B S^{9}$, Elaine H. Zackai, $M D^{5-7,9,10}$, and Paul P. Wang, $M D^{2,5,8}$

\begin{abstract}
Purpose: The purpose of this investigation is to describe the communication profile of children with the $22 \mathrm{q} 11.2$ deletion syndrome from infancy through school age and to examine the influence of other medical aspects, such as palate anomalies, learning disorders, and cardiac defects of the syndrome to communication. Methods: Seventy-nine children were examined using standardized tests of speech and language and perceptual measures of resonance and voice. Results: Results show significant delay in emergence of speech and language milestones with delay/disorder in speech-language processes persisting into the school aged years, including those children diagnosed with nonverbal learning disabilities. Persistent articulation and resonance disorders were also present, presumed to be related in part to palatal anomalies. No correlation was found between cardiac status, learning disorders, palate anomalies and communication disorders. Conclusion: The need for early identification and management of communication skills is crucial in the care of children with the 22q11.2 deletion. Genetics in
\end{abstract} Medicine, 2001:3(1):67-71.

Key Words: chromosome deletion, 22 11.2 deletion syndrome, language disorders, speech disorders, palate anomalies, heart defects

The 22q11.2 deletion syndrome is a genetic condition that affects nearly every organ and system. ${ }^{1}$ The range of clinical features is extensive and variable between affected individuals. Most commonly, congenital cardiac anomalies, palatal defects, immune deficiencies, hypocalcemia, developmental delay, learning disorders, mental retardation, dysphagia, and mild facial dysmorphism are seen. ${ }^{2}$

It is now known that the deletion accounts for a number of previously identified syndromes, including DiGeorge syndrome, velocardiofacial syndrome, conotruncal anomaly face syndrome and some isolated cases of conotruncal cardiac anomalies, Opitz G/BBB syndrome, and Cayler cardiofacial syndrome. ${ }^{3-10}$ The incidence of the chromosome $22 \mathrm{q} 11.2 \mathrm{de}-$ letion syndrome is reported to be $1: 4,000 .^{3}$ However, the incidence may actually prove to be higher as ascertainment improves. Our knowledge of this syndrome has expanded greatly since the advent and widespread availability of fluorescence in situ hybridization (FISH) chromosomal analysis. ${ }^{4,5}$

\footnotetext{
From the ${ }^{1}$ Center for Childhood Communication, ${ }^{2}$ Division of Child Development and Rehabilitation, ${ }^{3}$ Division of Plastic and Reconstructive Surgery, ${ }^{4}$ Department of Psychology, ${ }^{5}$ Department of Pediatrics, ${ }^{6}$ Department of Human Genetics and Molecular Biology, ${ }^{7}$ Department of Obstetrics and Gynecology, ${ }^{8}$ Children's Seashore House of the Children's Hospital of Philadelphia, ${ }^{9}$ The Children's Hospital of Philadelphia, ${ }^{10}$ The University of Pennsylvania School of Medicine, Philadelphia Pennsylvania.

Cynthia B. Solot, MA, CCC/SLP, Center for Childhood Communication, The Children's Seashore House of The Children's Hospital of Philadelphia, 34th and Civic Center Blvd., Philadelphia, PA 19104

Received: August 23, 2000.

Accepted: November 7, 2000.
}

Our knowledge of the communication features of the 22q11.2 deletion has expanded as more children have been identified and treated for their acute medical and developmental conditions. Feeding disorders, palate anomalies, delayed emergence of language, speech disorders, and language disorders have all been documented. ${ }^{11-14}$ Learning disorders ${ }^{10,15-18}$ have also been described in the literature. The diagnostic label nonverbal learning disability (NVLD) has been applied to this population by several investigators. ${ }^{15,16}$ That term describes a pattern of weakness in math skills with a Performance IQ lower than the Verbal IQ, and weak visual-spatial skills. It has also been reported that communication disorders are present very early, persist over time, and may constitute one of the most psychosocially difficult aspects of the deletion for patients and their families. ${ }^{11}$ The need for early identification, early intervention, and special education is crucial to reduce the impact of the disability and to advance communication skills.

\section{POPULATION AND METHODS}

As part of a multidisciplinary, prospective study, we examined the speech and language abilities of a large population of children with 22q11.2 deletion syndrome. Children were seen for evaluation by a team of medical and developmental specialists. Subjects were seen consecutively, according to enrollment in the study. Only those children receiving concurrent speechlanguage, plastic surgery, and psychological evaluations within a 6-month time period are described here. The population is divided into two groups: preschool and school aged. All chil- 
dren studied were confirmed to have the deletion by FISH analysis.

The purpose of this research effort is to review findings and describe a cross-sectional communication profile of children with 22q11.2 deletion syndrome and to examine the influence of other medical aspects of the syndrome, including palate anomalies, learning disorders, and cardiac defects on communication. We also examined whether language deficits would be found in children with a diagnosis of NVLD in the school aged population, given the high incidence of early delay in speech and language development. Effects of palatal intervention were reviewed. Implications for intervention based on findings and clinical experience are discussed.

In the preschool population, there were 53 children aged 7 to 66 months, including 29 males and 24 females. Cognitive assessments were administered in children up to the age of 42 months using the Bayley Scale of Infant Development, Second Edition $^{19}(N=40)$. This is a test designed to identify children with cognitive and motor delays. Children aged 42 to $66(N=$ 13) months were administered the Wechsler Preschool and Primary Scales of Intelligence-Revised. ${ }^{20}$ This is a frequently used intelligence test. Twenty-six children over the age of 5.6 years of age comprised the school aged population. There were 14 males and 12 females aged 5.9 to 16.7 years. The school aged children were given the Wechsler Intelligence Scale for Children-Third Edition. ${ }^{21}$ The WISC-III is a multifaceted intelligence test. For language testing, preschool children were administered the Pre-School Language Scale-3 (PLS). ${ }^{22}$ This test measures early language development, tapping into a broad range of comprehension (receptive) and expressive language skills. School aged children were administered the Clinical Evaluation of Language Fundamental-Revised (CELF-R).23 This test is designed to identify children in grades kindergarten through twelfth who lack the basic foundations of form and content of mature language use, including word meanings, word and sentence structure, and recall and retrieval. Scores are represented as receptive, expressive, and total language skills. All of the above tests have a mean of 100 and a standard deviation of 15 .

When sufficient speech was present, speech sound production was assessed on the Goldman Fristoe Test of Articulation, which tests production of each consonant sound of the English language.Criteria for normal speech were performance on the Goldman-Fristoe Test of Articulation ${ }^{24}$ above the 20th percentile and no perceptible prosodic disturbances, such as errors in rate, rhythm, intonation, and stress patterns. When there was insufficient speech to take a test, more informal assessments were made. Direct visualization studies were done, when possible and clinically indicated, to examine the structure and function of the palate. Nasometry measures were taken when indicated and clinically possible to assess degree of nasalance. Since it is widely accepted that the ear is the "first and primary" diagnostic tool ${ }^{25}$ only the results of a perceptual rating scale of nasality will be discussed in this report. Resonance was rated as hyponasal; normal; mildly, moderately, or severely hypernasal.
Voice was also perceptually evaluated, including ratings of pitch and quality.

\section{RESULTS}

The results are summarized in Table 1.

\section{Preschool children}

Preschool children were grouped into three levels of functional status according to the following criteria: Average, if the Bayley Mental Development Index or the Full Scale IQ was within one standard deviation of the mean; Mildly Delayed, if the MDI or Full Scale IQ was between one and two standard deviations below the mean; and Significantly Delayed, if the MDI or Full Scale IQ was two or more standard deviations below the mean. On cognitive testing, there were 10 children in the Average range. Twenty children were in the Mildly Delayed range, and 23 were in the Significantly Delayed range, showing a downward shift in IQ in this population. A similar downward trend was found in the results of the language testing. Twelve children were within one standard deviation of the mean. Twenty-six were one to two standard deviations of the mean, and 15 were below two standard deviations of the mean.

There is a strong relationship between cognitive and language findings. In the 10 children cognitively in the average range, the mean and standard deviation of the total language score (TLS) on the PLS was $88.6 \pm 11.1$. The mean and stan-

Table 1

Speech-language findings

\begin{tabular}{lcc}
\hline & Preschool & School-Aged \\
\hline$n$ & 53 & 26 \\
Age & $7-66$ mos & $5.9-16.7$ years \\
Cognitive & & \\
$\quad$ Bayley (40) & $68.6 \pm 13.3$ & \\
WPPSI (13) & $84.5 \pm 10.4$
\end{tabular}

WISC-III (26)

VIQ

$77.8 \pm 13.6$

PIQ

$71.7 \pm 12.8$

FSIQ

$73.0 \pm 12.6$

Language

PLS-3

CELF-R

$\begin{array}{lcc}\text { TLS } & 77.2 \pm 12.0 & 65.5 \pm 10.8 \\ \text { ELS } & 76.1 \pm 12.3 & 68.2 \pm 13.8 \\ \text { RLS } & 82.4 \pm 11.3 & 64.8 \pm 11.5 \\ \text { Articulation impairment } & 12 / 16 & 22 / 29 \\ \text { Voice impairment } & 19 / 32 & 9 / 29 \\ \text { Resonance impairment } & 29 / 32 & 20 / 29\end{array}$

WPPSI, Wechsler Preschool and Primary Scales of Intelligence; WISC-III, Wechsler Intelligence Scale for Children-Third Edition; VIQ, Verbal IQ; PIQ, Performance IQ; FSIQ, Full Scale IQ; RLS, receptive language score. 
dard deviation of the auditory comprehension (AC) subtest (receptive language) was $83.3 \pm 10.9$. The mean and standard deviation of the expressive language subtest (ELS) was $90.9 \pm$ 10. In the 20 children in the Mildly Delayed range, the mean and standard deviation of the TLS was $77.1 \pm 8.1$; the mean and standard deviation of AC was $82.7 \pm 8.1$; and the mean and standard deviation of ELS was76.0 \pm 9.3. In the 23 children in the Significantly Delayed range, the PLS results were as follows: TLS was $72.1 \pm 12$, AC was $78.6 \pm 12.2$, ELS was 70.7 \pm 11.7 . A total of $26 \%$ of children scored 10 or more points lower on language testing than on cognitive testing. These children were distributed across all three cognitive levels. In addition, expressive skills often lagged behind receptive skills. In $25 \%$ of the children, expressive language was 10 or more points lower than receptive language. In the group as a whole, expressive skills were lower than receptive skills $(P=0.0001)$.

One of the most striking features in this population is the near universality in delay of acquisition of language milestones. Ninety percent of 2 year olds were nonverbal or just using single words. Similarly, $80 \%$ of 3 year olds were nonverbal or just using words or simple phrases. By the time they were 4 years old, 30\% were still nonverbal or not yet speaking in sentences. This delay was often greater than the delay in general cognitive development. Among prelinguistic infants, many children were noted by observation and history to have decreased volume of babbling and decreased variety in sound play.

Because of the paucity of speech, only 16 preschool children over the age of 2 could be formally tested in the area of articulation. Only four children scored within normal limits (above the 20th percentile). Of the 32 children who used just a few words or phrases, and could imitate sufficiently to be assessed informally, a range of speech disorders were found, including motor speech disorders, compensatory disorders, and phonological, or developmental disorders. These patterns co-occurred in some subjects.

Motor disorders were seen in two-fifths of the population and were present in any or all of the speech subsystems, including respiration, phonation, articulation, and resonation. Such features as decreased facial animation, groping oral movements, poor imitation, poor stimulability, poor sequencing of sounds, strained-strangled voice, poor respiratory support, vocal fatigue at the end of a phrase, reduced syllables per breath, and/or impaired prosody (rhythm, intonation, stress patterns) were seen.

Compensatory articulation errors were seen in nearly a third of the children. These occur as a result of palatal anomalies (such as cleft palate, submucous cleft palate, and/or palatopharyngeal disproportion) that prevent the separation of the oral and nasal cavities. Compensatory errors might include glottal stops, exhalation substitutions, nasal substitutions, or decreased pressure on consonants.

Phonological error patterns were also seen in almost half of children, such as lisping, simplification of glides ( $r, y, l)$, as well as many other articulation or phonological error patterns.
These types of errors are commonly seen in the course of typical development.

Because of the high prevalence of palatal anomalies, including either structural and/or dynamic movement disorders, hypernasality was common. Only 3 of 32 children had perceptual resonance ratings which were within normal limits. Two were perceived to be hyponasal. Nine children were judged to be mildly hypernasal; six were judged to be moderately hypernasal, and seven were judged to be severely hypernasal. Five children did not have sufficient vocalizations to make a judgment.

In perceptual voice analysis, 13 children were judged to be in the normal range. Nineteen children were judged to have voice problems such as soft voice, breathiness, wet hoarseness, hoarseness, tense or strained voices. Some of the vocal problems were related to increased strain because of the palatal insufficiency. However, some of these vocal problems were presumed to be part of a broader motor speech disorder. One other notable finding is that of high pitch. Of 28 children with perceptual evaluations of pitch, voice was noted to be within normal limits in 15 (53.5\%) children and high in 13 children $(46.5 \%)$.

Another very common feature of the deletion is low muscle tone. This was frequently visualized in our population as flat facies, open mouth at rest, tongue protrusion, drooling, or palatal hypotonia. One third of the preschool group showed some facial asymmetries, such as asymmetric crying face, asymmetric movement on volitional lip rounding or retraction.

\section{School-aged children}

As is true in the preschool population, there is a downward distribution in IQ in the school aged children. The means and standard deviations using the WISC III are as follows: the Verbal IQ had a mean of 77.8 \pm 13.6 , the Performance IQ had a mean of $71.7 \pm 12.8$, and the Full Scale IQ had a mean of 73.0 \pm 12.6 .

The means and standard deviations of the Clinical Evaluation of Language Fundamentals-Revised (CELF) are as follows: Receptive Language Score was $64.8 \pm 11.5$; the Expressive Language Score was $68.2 \pm 13.8$ and the Total Language Score was $65.5 \pm 10.8$. These scores show a significant, persistent language deficit in children with the 22q11.2 deletion, particularly in expressive skills.

We performed a separate analysis of language skills in children who showed NVLD patterns. Even among these subjects, whose Verbal IQ scores were at least 10 points higher than Performance IQ scores, specific language impairment (SLI) was common (language impairment to a degree greater than general ability levels would suggest). Four of 11 (36\%) had SLI defined by language scores which were 10 or more points below cognitive skills with specific deficits in vocabulary, concepts, syntax, naming, narrative or descriptive language. Of the 15 children who did not have NVLD, $40 \%$ also had SLI. If we use less strict criteria and apply clinical history, school and functional performance, even more children showed signs of SLI. There was no correlation between diagnosis of a language disorder and IQ. That is, children with a high IQ were just as 
likely to have a language disorder as a child with a lower IQ. There was also no correlation between language, speech, palate, or cardiac findings.

In the area of speech, 29 school aged children were administered the Goldman Fristoe Test of Articulation. Only seven children had normal speech. The remaining children showed speech abnormalities of varying kinds, including phonological, compensatory, and motor errors. These occurred either alone or in combinations. This is highly significant and does not vary with mean IQ or total CELF-R scores. Compensatory errors such as decreased pressure on consonants and motor errors, often in rate and rhythm persist into late childhood and adolescence.

Nine of 29 children demonstrated abnormal voice findings, including hoarseness and decreased loudness. Six children had high pitch. These findings did not correlate with any known laryngeal anomalies in these subjects.

Palatal evaluations showed that 20 of the 29 children had velopharyngeal insufficiency or disproportion (VPI) confirmed by direct visualization studies. Each child showed varying degrees of hypernasality ranging from mild to moderate to severe. Fourteen of the 20 children had at least one surgical procedure to manage VPI, at our center or elsewhere, and only 4 had normal-to-hyponasal speech, with the balance continuing to exhibit some degree of postsurgical hypernasality.

\section{DISCUSSION}

These results reveal a wide range of communication deficits in children with the 22q11.2 microdeletion syndrome across the age spectrum. Findings include (1) delayed emergence of language and prolonged periods between milestones; (2) speech and language disorders that continue into the school aged years in at least half the population; (3) hypernasality related to palate anomaly, and (4) voice disorders, in a small portion of the population.

The incidence of palatal abnormalities is high, ranging from $46 \%{ }^{26}$ to $69 \%{ }^{27}$ This number may be even higher as $14 \%$ in the one study ${ }^{27}$ were too young to make a definitive diagnosis. An important observation is that many of our children remained hypernasal after surgical intervention. Thus, even with pharyngoplasty, resonance improved but did not reach normal levels in a majority of children. This may be related to patterns of hypotonia of the VP mechanism and/or muscle hypoplasia (Kirschner, unpublished data).

The fact that many of the perceived voice findings did not correlate with any known laryngeal abnormality suggests a possible subtle and variant manifestation of the deletion to the laryngeal structures. Significant laryngeal and tracheal anomalies have been described in a small portion of the population, including laryngomalacia, laryngeal web, unilateral vocal fold paralysis, subglottic stenosis, tracheoesophageal fistula, tracheomalacia, laryngeal cleft, and epiglottic abnormalities ${ }^{28,29}$ (Jacobs, unpublished data).

Because the effect of the deletion on early development is so widespread and devastating to early communication and be- havior, every child with the deletion should be considered at risk and should, therefore, be enrolled in early intervention settings as soon as a diagnosis is made. A proactive stance is recommended in the management of these patients. Early oral motor problems may contribute to feeding difficulties (as can other medical conditions such as gastrointestinal problems) and can be addressed in the newborn period to reduce the impact of the disability. Direct speech-language therapy should be instituted at the first sign of a delay or disorder. Development of early receptive and expressive language skills is critically important as is development of higher level skills as the children mature. Phonological placement therapy and extinguishment of compensatory articulation should be stressed in direct, individual speech therapy, shaping vocalizations into vowels and properly placed consonants. There is no scientific evidence to support the notion that strengthening an oral structure in nonspeech activities will lead to improved speech.

Each child should receive speech-language evaluation and palatal evaluation as part of a core diagnostic evaluation and these should be repeated at regular intervals to assess progress and changing needs. Some younger children benefit from evaluations at 6-month intervals, while others may need yearly evaluations. Serial evaluations in conjunction with a plastic surgeon or otolaryngologist will help to determine readiness for surgical intervention for VPI.

In the period when language has not yet emerged, we strongly advocate the use of Total Communication, which is the use of manual signs and speech stimulation simultaneously. ${ }^{11}$ Our experience, as well as the experience with typically developing children and other disabled populations, shows that once speech emerges, manual signs are dropped in place of oral productions, even in the presence of speech disorders. It is our experience that early signing, when there is no speech, enhances reciprocal interactions and communicative exchanges, reduces frustration, and builds a bridge toward more conventional communicative exchanges. It is a form of multisensory therapy. This approach benefits children who are able to symbolize but cannot do so verbally. Moreover, while the specific language and speech of a culture are learned, children are biologically primed to develop language and speech along remarkably similar universal sequences. If they do not (develop spoken language and speech) because of some effect of the deletion on early language learning processes, they need to be provided with an alternative modality for communication, lest their critical period for language acquisition be jeopardized.

Once speech emerges in children with a 22q11.2 deletion, it is often impaired by typical (phonological) and nontypically occurring processes (motor disorders and compensatory disorders). Also, in addition to delayed emergence of milestones, children with the deletion seem to have prolonged periods between milestones. As a result, therapy must be intensive and individualized. In the current economic times, this can be a challenging recommendation given reimbursement patterns and school trends toward inclusion methods of therapy. However, our experience (as well as that of others ${ }^{30}$ ) shows that children receiving the most intensive therapies in conjunction 
with special education show the most improvement. Developing parental advocacy is also an important part of the treatment process.

Children with a 22q11.2 deletion should be treated by a multidisciplinary team of professionals; both medical and developmental teams are necessary for proper evaluation and treatment. For example, some of the motor and perceptual problems evidenced in these children must also be addressed in occupational and physical therapies.

In the school aged population, the data from this cohort show that speech and language problems persist and require in-depth, comprehensive evaluation and treatment when indicated. Very importantly, the diagnosis of an NVLD does not rule out an SLI. The early delay in language emergence continues to manifest itself in a high proportion of SLI in the school aged period. The label of "NVLD" is potentially confusing as these results clearly demonstrate that language disorders are very common in children with the 22q11.2 deletion, even when an NVLD profile is present. It is important to recognize that language measures examine different functions than the verbal knowledge tested in the verbal sections of IQ tests. Speech and language therapy, with special education as indicated, continues to be an important part of the basic care of children with this deletion. Because of the impact of language on learning, classroom accommodations are often necessary.

Although 22q11.2 deletion is closely associated with cleft palate, cardiac anomalies and other major malformations, children with this deletion may present early with feeding, communication, palatal dysfunction and no obvious structural anomalies. Some of the more mildly affected children may not present in cleft palate clinics, ENT clinics or speechlanguage clinics until later in their development. ${ }^{31}$ It is important to expand ascertainment and treatment by locating children in these settings as well as other more obvious ones, such as cardiac clinics. This can help us in our ultimate goal of best advocating for and treating the children and families affected by the 22q11.2 deletion syndrome.

These studies were supported by funds from the National Institutes of Health, including DC02027, HL62177, and HD26979.

\section{References}

1. Shprintzen RJ. Velo-cardio-facial syndrome: a distinctive behavioral phenotype. Ment Retard Dev Disabil Res Rev 2000;6:142-147.

2. McDonald-McGinn DM, Kirschner R, Goldmuntz E, Sullivan K, Eicher P, Gerdes M, Moss E, Solot C, Wang P, Jacobs I, Handler S, Knightly C, Heher K, Wilson M Ming JE, Grace K, Driscoll D, Pasquariello P, Randall P, LaRossa D, Emanuel, BS, Zackai EH. The Philadelphia story. The 22q 11.2 deletion: report on 250 patients. Genet Couns 1999;10:11-24.

3. Burn J, Goodship J. Congenital heart disease. In: Rimoin DL, Connor JM, Pyeritz RE, Emery AEH, editors. Emery and Rimoin's principles and practice of medical genetics. Vol 1. Edinburgh: Churchill Livingstone, 1993:767-803.

4. Driscoll DA, Budarf ML, Emanuel BS. A genetic etiology for DiGeorge syndrome: consistent deletions and microdeletions of 22q11. Am J Hum Genet 1992;50:924-933.

5. Driscoll DA, Spinner NB, Budarf ML, McDonald-McGinn DM, Zackai EH, Goldberg RB, Shprintzen RJ, Saal HM, Zonana J, Jones MC, Mascarello JT, Emanuel BS. Deletions and microdeletions of 22q11.2 in Velo-cardio-facial syndrome. Am J Med Genet 1992;44:261-268.
6. Gianotti A, Diglio MC, Marino B, Mingarelli R, Dallapicolla B. Caylor cardiofacial syndrome and deletion 22q11: part of the Catch 22 phenotype. Am J Med Genet 1994;53:303-304

7. Goldmuntz E, Driscoll D, Budarf ML, Zackai EH, McDonald-McGinn DM, Biegel JA, Emanuel BS. Microdeletions of chromosomal region 22q11 in patients with congenital conotruncal cardiac defects. J Med Genet 1993;30:807-812.

8. Matsuoka R, Takao A, Kimura M, Imamura S-I, Kondo C, Joh-o K, Ikeda K, NishiBatake M, Ando M, Momma K. Confirmation that the conotruncal anomaly face syndrome is associated with a deletion within 22q11.2. Am J Med Genet 1994;53:285-289.

9. McDonald-McGinn DM, Driscoll DA, Bason L, Christenson K, Lynch D, Sullivan K, Canning D, Zavod W, Quinn N, Rome J, Paris Y, Weinberg P, Clark BJ, Emanuel BS, Zackai EH. Autosomal dominant. “Opitz” G/BBB syndrome due to a 22q11.2 deletion. Am J Med Genet 1995;59:103-112.

10. Shprintzen RJ, Goldberg RB, Lewin ML, Sidoti EJ, Berkman MD, Argamaso RV, Young D. A new syndrome involving cleft palate, cardiac anomalies, typical facies and learning disabilities: velo-cardio-facial syndrome. Cleft Palate J 1978;5:56-62.

11. Solot CB, Knightly C, Handler SD, Gerdes M, McDonald-McGinn D, Moss E, Wang P, Cohen M, Randall P, Larossa D, Driscoll D, Emanuel B, Zackai E. Communication disorders in the 22q11.2 microdeletion syndrome. J Commun Disord 2000;3:1-18.

12. Gerdes M, Solot C, Wang PP, Jawad A, DaCosta AM, LaRossa D, Randall P, Goldmuntz B, Clark BJ III, Driscoll DA, Emanuel BS, McDonald-McGinn DM, Batshaw ML, Zackai EH. Cognitive and behavioral profiles of preschool children with chromosome 22q11.2 microdeletion. Am J Med Genet 1999;85:127-133.

13. Eicher P, Fox C, McDonald-McGinn DM, Driscoll DA, Emanuel BS, Zackai E. Dysphagia in patients with 22q11.2 deletion: report of 51 patients. J Pediatr In press.

14. Scherer NJ, D'Antonio LL, Kalbfleisch JH. Early speech and language development in children with velocardiofacial syndrome. Am J Med Genet 1999;88:714-723.

15. Moss EJ, Batshaw ML, Solot C, Gerdes M, McDonald-McGinn DM, Driscoll D, Emanuel BS, Zackai EH, Wang P. Psychoeducational profile of the 22q11.2 microdeletion syndrome. J Pediatr 1999;134:193-198.

16. Swillen A, Devriendt E, Legius E, Eyskens B, Dumoulin M, Gewillig M, Fryns JP. Intelligence and psychosocial adjustment in velocardiofacial syndrome: a study of 37 children and adolescents with VCFS. J Am Med Genet 1997;34:453-458.

17. Golding-Kushner KJ, Weller G, Shprintzen RJ, Velo-cardio-facial syndrome: language and psychological profiles. J Craniofac Genet Dev Biol 1985;5:259-266.

18. Kok LK, Solman RT. Velocardiofacial syndrome: learning difficulties and intervention. J Med Genet 1995;32:612-618.

19. Bayley N. Bayley Scales of Infant Development-2nd Ed. San Antonio, TX: American Psychological Corporation, 1993.

20. Wechsler D. Wechsler Preschool and Primary Scales of Intelligence-Revised. San Antonio, TX: Psychological Corporation, 1989.

21. Wechsler D. Wechsler Intelligence Scale for Children-3rd Ed. San Antonio, TX: Psychological Corporation, 1991.

22. Zimmerman I, Steiner V, Pond R. Pre-School Language Scale-3rd Ed. San Antonio, TX: Psychological Corporation, Harcourt Brace Janovitch, Inc., 1992.

23. Semel E, Wiig E, Secord W. Clinical Evaluation of Language Fundamentals-Revised. San Antonio, TX: Psychological Corporation, Harcourt Brace Janovitch, Inc., 1986.

24. Goldman R, Frisote M. The Goldman Fristoe test of articulation. Circle Pines, MN: American Guidance Service, 1986.

25. Kuehn DP, Moller KT. The state of the art: speech, and language issues in the cleft palate population. Cleft Palate Craniofac J 2000;37:348.

26. Ryan AK, Goodship AJ, Wilson DI, Philip N, Levy A, Seidel H, Schuffenhauer S, Oechler H, Belohradssky B, Prieuer M, Aurias A, Raymond FL, Clayton-Smith J, Hatchwell E, McKeown C, Beemer FA, Dallapiccola B, Hurst JA, Ignatius J. Spectrum of clinical features associated with interstitial chromosome 22q11deletions: a European collaborative study. Am J Med Genet 1997;86:359-365.

27. McDonald-McGinn DM, LaRossa D, Goldmuntz E, Sullivan K, Eicher P, Gerdes M, Moss E, Wang P, Solot C, Schultz P, Lynch D, Bingham P, Keenan G, Weinzeimer S, Ming J, Driscoll D, Clark BJ, Markowitz R, Cohen A, Moshang T, Pasquariello P, Randall P, Emanuel B, Zackai E. The 22q11.2 deletion: screening for deletion, diagnostic workup, and outcome of results. report on 181 patients. Genet Test 1997;1:99-108.

28. LeBlanc EM, Gereau S, Bassila M. Prevalence of laryngeal anomalies in velocardiofacial syndrome. Paper presented at the annual meeting of the American Cleft Palate Craniofacial Association, 1996, San Diego, CA.

29. Williams S, Tatum S, Casper J, Grundfast K, Shprintzen RJ. Unilateral vocal fold paresis in velocardiofacial syndrome. Paper presented at the 25th meeting of The Society for Ear, Nose, and Throat Advances in Children, 1997, St Petersberg, FL.

30. Albery L, Enderby P. Intensive therapy for cleft palate children. Br J Disord Commun 1984;19:115-124.

31. Wang PP, Solot C, Moss EM, Gerdes M, McDonald-McGinn DM, Driscoll DA, Emanuel BS, Zackai EH. Developmental presentation of 22q11.2 deletion (DiGeorge/velocardiofacial syndrome). J Dev Behav Pediatr 1998;19:342-345. 